\title{
Health care costs associated with gestational diabetes mellitus among high-risk women - results from a randomised trial
}

\author{
Päivi Kolu ${ }^{1 *}$, Jani Raitanen ${ }^{1,2}$, Pekka Rissanen² and Riitta Luoto
}

\begin{abstract}
Background: The costs of gestational diabetes mellitus (GDM) screening have been frequently reported, but total GDM-related health care costs compared to the health care costs of women without GDM have not been reported. The aim of this study was to analyse GDM-related health care costs among women with an elevated risk of GDM.

Methods: The study was based on a cluster-randomised GDM prevention trial $(N=848)$ carried out at maternity clinics, combined with data from the Finnish Medical Birth Register and Care Registers for Social Welfare and Health Care. Costs of outpatient visits to primary and secondary care, cost of inpatient hospital care before and after delivery, the use of insulin, delivery costs and babies' stay in the neonatal intensive care unit were analysed. Women who developed GDM were compared to those who were not diagnosed with GDM.

Results: Total mean health care costs adjusted for age, body mass index and education were $25.1 \%$ higher among women diagnosed with GDM ( $€ 6,432$ vs. $€ 5,143, p<0.001)$ than among women without GDM. The cost of inpatient visits was $44 \%$ higher and neonatal intensive care unit use was $49 \%$ higher in the GDM group than among women without GDM. The delivery costs were the largest single component in both groups.

Conclusions: A confirmed GDM diagnosis was associated with a significant increase in total health care costs. Effective lifestyle counselling by primary health care providers may offer a means of reducing the high costs of secondary care.
\end{abstract}

Keywords: Cost, Gestational diabetes mellitus, Primary health care

\section{Background}

Gestational diabetes mellitus (GDM) is a term for diabetes first appearing during pregnancy and diagnosed with a glucose tolerance test [1]. The risk of GDM is associated with low physical activity, being overweight, and GDM in an earlier pregnancy [2-5]. In Finland the prevalence of GDM was $10.3-11.2 \%$ according to the Medical Birth Register for the period 2004-2006 [6]. GDM is a growing public health concern [7] and is associated with increased overall health care costs [8]. According to earlier research, women with GDM had $18 \%$ higher delivery stay costs than women without GDM [9]. In addition, antenatal outpatient costs due to

\footnotetext{
*Correspondence: paivi.kolu@uta.fi

'UKK Institute for Health Promotion Research, Kaupinpuistonkatu 1, FI-33501, Tampere, Finland

Full list of author information is available at the end of the article
}

visits to primary and secondary care were $25 \%$ higher among women with GDM than among women without a GDM diagnosis [10]. However, overweight $(\mathrm{BMI} \geq 25)$ as a risk factor for GDM was associated with increased inpatient and outpatient visits during pregnancy $[11,12]$.

GDM increases the postnatal health care burden due to an increased risk of neonatal complications, such as shoulder dystocia [13], foetal malformations [14] and, type 2 diabetes later in life $[15,16]$. There is an increasing trend in the incidence of GDM $[7,17]$, which will consume more health care resources in the future. Thus cost analysis is a method of measuring the use of resources and describing the allocation of costs within the health care sector, and may help to create more cost-effective treatment procedures. To the best of our knowledge, there are no reports on the GDM risk group comparing the pre- and postnatal health care costs for

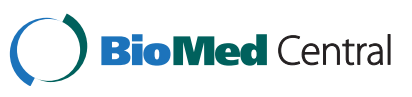


women with GDM, and for women without a GDM diagnosis, but there are several studies related to the costs of screening [18-20]. We have previously reported the outcomes of GDM prevention in a clusterrandomised trial [21,22]. The aim of the original trial was to assess whether the occurrence of GDM can be prevented by dietary and physical activity counselling. As a result of the GDM prevention trial lower neonatal birthweight was seen in the intervention group compared to the group offered usual care, a favourable change in the consumption of fatty acids and saccharose intake in the intervention group. In addition, in the intervention group there was a smaller decrease in MET minutes per week for at least moderate intensity activity [22]. The aim of the present study was to describe GDM-associated health care costs between women with and without at least one GDM risk factor.

\section{Methods}

This cost analysis was based on data from a clusterrandomised GDM prevention trial $(\mathrm{N}=848)$, conducted at maternity clinics in Finland in the period from 2007 to 2009. During pregnant women's routine visits to the maternity clinic, public health nurses recruited all women up to 12 weeks pregnant. The inclusion criteria of the original study were: $\mathrm{BMI} \geq 25 \mathrm{~kg} / \mathrm{m}^{2}$, previous occurrence of GDM, or any signs of glucose intolerance, a macrosomic newborn $(\geq 4500 \mathrm{~g})$ in any earlier pregnancy, type 1 or 2 diabetes in first- or second-degree relatives or age $\geq 40$ years. Women included in the trial were either primigravida or multigravida with singleton pregnancies. The exclusion criteria were: pathological value in baseline oral glucose tolerance test (OGTT) at 8-12 weeks' gestation (blood glucose $>5.3 \mathrm{mmol} / \mathrm{l}$ at fasting, $>10.0 \mathrm{mmol} / \mathrm{l}$ at 1 -hour or $>8.6 \mathrm{mmol} / \mathrm{l}$ at 2 hour), type 1 or 2 diabetes before pregnancy, inadequate Finnish language proficiency, age $<18$ years, twin pregnancy or physical limitation preventing physical activity.

In the present study, the case definition of GDM included women with a pathologic oral glucose tolerance test or ongoing insulin treatment. Women exhibiting no GDM diagnostic criteria formed a comparison group. The cost comparison included health care costs accruing to the municipality of residence and to the patient. The costs were evaluated from a societal perspective, including costs to the patient. This is because, in the tax-based health care system in Finland, the patients' municipality of residence reimburses the real health care costs to the relevant hospital district. However, the daily charges for outpatient- and inpatient care also create a small cost to the patient. The cost analysis included all eligible women from the GDM prevention trial who had signed a studyparticipant consent form and had given us their permission to use their data in the Medical Birth Register and the Care Registers for Social Welfare and Health Care. Because the travel expenses and time costs related to the use of health services were assumed to be minor, they were not included in the calculation.

Costs were taken into account from the beginning of the pregnancy until the last day that the mother and her newborn spent in hospital after the birth. Information concerning medication and the number of visits to primary and secondary care was obtained from maternity cards filled in by the public health nurse at the maternity clinic. Information on visits to a diabetes nurse or a dietician was collected from questionnaires filled in by the mothers at the beginning of the study (at 8-13 gestational weeks) and again at $26-28$ and at $37-39$ gestational weeks. The information on the number of the mother's inpatient hospital days before and after the standard delivery stay, the mode of delivery, the ICD-10 diagnosis code of the mother and newborn and the number of hospital days of the newborn were obtained from the Medical Birth Register and the Care Register.

Primary health care costs were based on the average national unit costs for health care, which includes visits to the public health nurse and to the doctor [23]. The costs of visits to secondary care, visits to a diabetes nurse and a dietician, the modes of delivery, inpatient days and neonatal intensive care units use were estimated by using the unit costs of the Tampere University Hospital, which was the hospital in which $93 \%$ of the deliveries took place and is the second largest hospital in Finland [24]. The unit costs were entered at the price level for 2009. Unit costs of obstetric outpatient and inpatient care included salary costs and administrative expenses, laboratory expenses as well as costs for all professionals participating in the provision of health care.

The cost evaluation included only inpatient days preceding and following delivery in hospital units related to pregnancy and GDM. The standard inpatient daily charge of 30 Euros was added to the unit cost, which was the cost to be paid by the patient. In the cost analysis, pre-delivery inpatient days were counted until the delivery and during the immediate post-partum period after delivery using the average national inpatient day cost [23]. Delivery cost and inpatient day costs due to delivery were counted separately using the Tampere University Hospital unit cost [24], which was used to obtain detailed DRG (Diagnosis Related Groups) information. Delivery unit costs included a standard number of inpatient days, depending on the mode of delivery. In addition, delivery-related operation costs included the salary costs of obstetric staff, including administrative expenses, medication and the cost of neonatal care in cases without an ICD-diagnosis. The newborn babies' hospital stays were calculated separately in cases when 
the newborn needed care in a neonatal intensive care unit because of a disease involving organic complications or another ICD-10 diagnosis.

If the newborn had an ICD-10 diagnosis code, the costs of the newborn's care were evaluated using the classification of the delivery hospital, where the costs of newborn babies were allocated to one of three possible unit cost categories, depending on the newborns' birthweight, ICD-10 diagnosis code and the number of inpatient days in hospital. In the case of rooming-in, the costs of the newborn baby's care were included in the mother's delivery unit cost.

Medication costs included insulin costs but not the costs of glucose monitoring at home, as these were known to be minor [23]. Insulin costs were calculated for a period of 2.5 months and included health insurance reimbursements. According to the Finnish national guidelines, insulin treatment should be started, if necessary, at the 30th gestational week and should continue until delivery [25]. The costs of the oral glucose tolerance test (OGTT) as a diagnostic test for GDM were assumed to have been incurred once in both groups. In the original study, a pathologic OGTT result at 8-12 weeks' gestation was a criterion for exclusion from the study, which meant that a large amount of information concerning the costs of OGTT was missed $(\mathrm{N}=174)$.

\section{Statistical analysis}

The association between the groups and continuous variables was tested with the Mann-Whitney U-test and with the chi-square test for categorical variables. Costs were reported as means and were rounded to whole Euros. Mann-Whitney U-test was used to analyse the differences between the two groups. Ratios or proportions of prenatal complications and mode of delivery variables were calculated using the chi-square test or, if the assumptions of the chi-square tests were not valid, Fisher's exact test. Total costs were adjusted for maternal age, body mass index and education. These adjustments were performed using ordinal regression analysis, because cost distributions were not normally distributed. The results were considered to be statistically significant if $\mathrm{p}<0.05$. All analyses were performed using SPSS software (version 19).

\section{Results}

From a total of 848 women with an elevated risk of GDM, $251(29.6 \%)$ had a confirmed GDM diagnosis by the end of the pregnancy, while 597 women (70.4\%) formed a comparison group (Table 1). At the beginning of pregnancy the mean age of the GDM group was 30.6 years, and in the comparison group 29.2 years $(\mathrm{p}<0.001)$. Women with a GDM diagnosis were significantly more overweight ( 28.8 vs. $\left.24.9 \mathrm{~kg} / \mathrm{m}^{2} ; \mathrm{p}<0.001\right)$, were more likely to have been diagnosed with GDM in earlier pregnancies $(\mathrm{p}<0.001)$ and had a greater number of previous deliveries $(\mathrm{p}<0.016)$. In contrast, there were no statistical correlations between a GDM diagnosis and the level of education or smoking habits. The sum of GDM risk factors was higher among women with GDM (1.51 vs. 0.92, $\mathrm{p}<0.001$ ) than among women without GDM (Table 1). There were no statistically significant differences between groups in prevalence of diseases such as elevated blood pressure, high blood cholesterol, diabetes, cardiovascular diseases, cancer, rheumatoid arthritis, bronchitis, depression or back problems (not shown in table).

The adjusted mean total health care costs to the municipality and the patient were $25.1 \%$ higher among women diagnosed with GDM (€6,432 vs. $€ 5,143, \mathrm{p}<0.001$, Table 2). In addition, the use of insulin as a way to measure the severity of GDM was associated with higher total costs $(€ 7,026$ vs. $€ 5,766, \mathrm{p}<0.001)$. The mean cost of visits to a public health nurse and to a doctor were slightly lower in the GDM group ( $€ 1,008$ vs. $€ 1,048, \mathrm{p}=0.019)$. The mean cost of visits to secondary care was 2.3 times higher for women diagnosed with GDM ( $€ 676$ vs. $€ 291, \mathrm{p}<0.001)$. Although the costs were minor, GDM was associated with increased costs $(€ 40$ vs. $€ 1, p<0.001)$ resulting from visits to a diabetes nurse, but there was no difference in the mean costs of visits to a dietician ( $\mathrm{p}=0.79$ ). Insulin therapy was used by $29.1 \%$ of women diagnosed with GDM. The medication costs during the 2.5 month calculation period were $€ 85$, of which the proportion refunded by the Social Insurance institution of Finland was $42 \%$ of the total cost directly to the patient. The mean cost of total inpatient days before and after delivery was $44 \%$ higher in the GDM group ( $€ 491$ vs. $€ 341, \mathrm{p}<0.001$ ) than in the comparison group.

There were no statistical differences between the groups in terms of delivery cost to the patient ( $€ 105$ vs. $€ 101, \mathrm{p}=0.14$ ). Also, the delivery cost to the municipality of residence was only slightly higher for women diagnosed with GDM than for women without GDM $(€ 2,144$ vs. $€ 2,048, \mathrm{p}=0.051$, Table 3$)$. GDM was associated with a higher rate of labour induction $(27.1 \%$ vs. $13.9 \%, \mathrm{p}<0.001$, Table 4). The proportion of elective and emergency caesarean sections was higher in the GDM group (21.1\% vs. $14.9 \%$ ), whereas vaginal delivery was more frequent in women without a GDM diagnosis $(78.9 \%$ vs. $85.1 \%$, Table 4$)$. As for the newborn baby, resuscitation was needed more often in the GDM group ( 5 vs. $1, \mathrm{p}<0.010$ ). There were no statistical correlations between the groups in other prenatal complications or health outcomes (Table 4).

Costs of outpatient visits both to primary and secondary care clinics were $28.6 \%$ higher, and inpatient service costs were $44 \%$ higher among women with GDM than among women without GDM (Table 5). The cost of 
Table 1 Characteristics (mean \pm SD or frequency and percentage) and distribution of risk factors of GDM of women with and without GDM

\begin{tabular}{|c|c|c|c|c|c|}
\hline & Women with GDM & Missing & Comparison groupt & Missing & p-value \\
\hline & ${ }^{*} n=251$ & & $n=597$ & & \\
\hline \multicolumn{6}{|l|}{ Age categories } \\
\hline-29 & $102(40.6)$ & & $312(52.3)$ & & \\
\hline $30-34$ & $90(35.9)$ & & $200(33.5)$ & & \\
\hline $35+$ & $59(23.5)$ & 0 & $85(14.2)$ & 0 & 0.001 \\
\hline \multicolumn{6}{|l|}{ BMI categories } \\
\hline Normal $\left(<25 \mathrm{~kg} / \mathrm{m}^{2}\right)$ & $67(27.0)$ & & $345(57.8)$ & & \\
\hline Overweight ( 25 to $29.9 \mathrm{~kg} / \mathrm{m}^{2}$ ) & $91(36.7)$ & & $175(29.4)$ & & \\
\hline Obese $\left(>=30 \mathrm{~kg} / \mathrm{m}^{2}\right)$ & $90(36.3)$ & 3 & $76(12.8)$ & 1 & $<0.001$ \\
\hline \multicolumn{6}{|l|}{ Education levelf } \\
\hline Low & $98(40.5)$ & & $192(33.4)$ & & \\
\hline Medium & $94(38.8)$ & & $254(44.3)$ & & \\
\hline High & $50(20.7)$ & 9 & $128(22.3)$ & 23 & 0.15 \\
\hline Previous deliveries & $1.10 \pm 1.18$ & 0 & $0.89 \pm 0.99$ & 0 & 0.016 \\
\hline \multicolumn{6}{|l|}{ Smoking during pregnancy } \\
\hline No & $225(91.8)$ & & $556(93.7)$ & & \\
\hline Stopped during first trimester & $6(2.4)$ & & $11(1.9)$ & & \\
\hline Continued smoking after first trimester & $14(5.7)$ & 6 & $26(4.4)$ & 4 & 0.60 \\
\hline Gestational diabetes in any earlier pregnancy & $64(28.3)$ & 4 & $38(7.3)$ & 17 & $<0.001$ \\
\hline \multicolumn{6}{|l|}{ Risk factors of GDM } \\
\hline $\mathrm{BMI} \geq 25 \mathrm{~kg} / \mathrm{m}^{2}$ & $181(73.3 \%)$ & 4 & $247(42.8 \%)$ & 20 & $<0.001$ \\
\hline Macrosomic children in earlier pregnancy & $14(5.7 \%)$ & 4 & $12(2.1 \%)$ & 20 & 0.007 \\
\hline GDM in earlier pregnancy & $64(25.9 \%)$ & 4 & $38(6.6 \%)$ & 20 & $<0.001$ \\
\hline Diabetes in relatives & $106(42.9 \%)$ & 4 & $227(39.3 \%)$ & 20 & 0.34 \\
\hline Age $\geq 40$ years & & 4 & $7(1.2 \%)$ & 20 & 0.099 \\
\hline Polycystic ovarian syndrome & 0 & 4 & $1(0,2 \%)$ & 20 & 1.00 \\
\hline Sum of risk factors & $1.51(0.74)$ & 4 & $0.92(0.75)$ & 20 & $<0.001$ \\
\hline
\end{tabular}

*Inclusion criteria (one or more): pathologic oral glucose tolerance test, initiated insulin treatment during pregnancy, diagnosed GDM.

tWithout GDM diagnostic criteria.

fLow $=$ vocational school or less.

Medium = polytechnic level.

High $=$ academic education

delivery to the patient and the municipality was only slightly (4.7\%) higher among women diagnosed with GDM, and was the largest single component of the mean costs in both groups. GDM was associated with $49 \%$ higher costs for treatment in a neonatal intensive care unit immediately after the birth than for the infants of mothers without GDM.

\section{Discussion}

A confirmed GDM diagnosis was associated with a significant increase in total health care costs. In addition to increased costs to the patient and to the municipality of residence, GDM was also associated with more frequent elective and emergency caesarean sections, which, in turn, is associated with an increased risk of adverse maternal outcomes [26]. On the other hand, the greater number of caesarean sections in the GDM group may explain the small number of delivery complications, such as bone fractures and shoulder dystocia occurring in the GDM group.

Visits to primary health care providers were not correlated with GDM, which is partly explained by the national guidelines concerning GDM. In Finland the municipalities provide antenatal care services for all pregnant women free of charge. Almost all pregnant women (99.7\%) utilize municipal maternity care services, although there are also private services available [27], which minimized the amount of missing information. Women who are pregnant for the first time make a total of 14-18 visits to a public health nurse or a doctor in an 
Table 2 Use of health care services (mean and SD or frequency and percentage) and mean costs per person during pregnancy and postnatal period

\begin{tabular}{|c|c|c|c|c|}
\hline \multirow{2}{*}{ Unit cost, $€$} & \multicolumn{2}{|c|}{ Number of units } & \multicolumn{2}{|c|}{ Mean cost, $€^{*}$} \\
\hline & Women with & Comparison & Women with & Comparison \\
\hline & GDM $(n=251)$ & group $(n=597)$ & GDM $(n=251)$ & group $(n=597)$ \\
\hline
\end{tabular}

\section{Women}

Visits to primary care

Visits to secondary care

Visits to a diabetes nurse

Visits to a dietician

$\begin{array}{ccc}72 € / \text { visit } & 14.0 \pm 3.3 & 14.6 \pm 2.8 \\ 208 € / \text { visit† } & 3.25 \pm 2.9 & 1.40+/-1.6 \\ 91 € / \text { visit† } & 0.44 \pm 0.86 & 0.01 \pm 0.13 \\ 164 € / \text { visit† } & 0.01 \pm 0.12 & 0.01 \pm 0.14 \\ 25 € / \text { test } & & \end{array}$

OGTT

Insulin therapy

Hospital days before and after delivery

$85 € / 2.5$ month

$73(29.1 \%)$

\section{$0(0.0 \%)$}

$330 € /$ day

$1.49 \pm 2.70$

$1.03 \pm 2.20$

$3.51 \pm 1.22$

$3.37 \pm 1.14$

$\begin{array}{ccl}1,008 & 1,048 & 0.019 \\ 676 & 291 & <0.001 \\ 40 & 1 & <0.001 \\ 2 & 2 & 0.79 \\ 25 & 25 & \\ 25 & - & <0.001 \\ 491 & 341 & <0.001 \\ 105 & 101 & 0.14 \\ 2,144 & 2,048 & \end{array}$

Delivery cost to the municipality (Table 3)

$30 € /$ da

2,144

Newborn

Cost of neonatal intensive care unit to the patient§

Cost of neonatal intensive care unit to the municipality (Table 3)

$1,783 \quad 154$
$6,432 \quad 5,143$

Total mean costs, $€$

Unadjusted

Adjusted II

*Costs are rounded to whole Euros.

tIncluding outpatient charge $(27 €$ per visit).

₹ Including standard inpatient daily charge ( $30 €$ per day) and all costs to municipalities and patients.

$\S$ Inpatient daily charge ( $30 €$ per day) during 1-7 hospital days.

I|Adjusted for maternal age, body mass index and education.

Table 3 Mean costs of delivery and treatment in a neonatal intensive care unit among women with risk of GDM

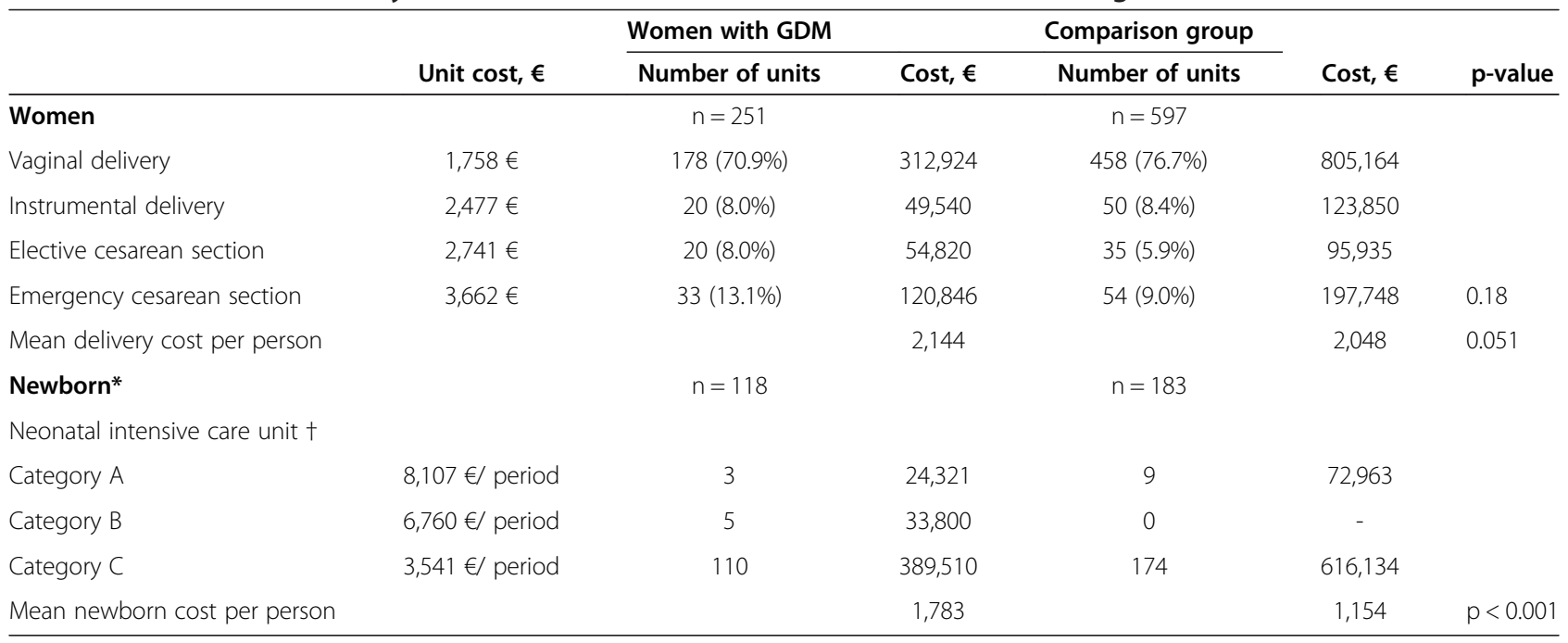

*Newborns without ICD-10 diagnosis were not included.

+Category A: Birthweight 1500-2499 g, inpatient days 1-22, including required examinations and treatments and $\leq 2$ diseases with organic complications. Category B: Birthweight $>2500 \mathrm{~g}$, inpatient days $1-11$, including required examinations and treatments and $\geq 1$ disease with organic complications. Category C: Birthweight $>2500 \mathrm{~g}$, inpatient days $1-7$, including required examinations and treatments. No disease with organic complications. 
Table 4 Mode of delivery and prenatal complications/ health outcomes

\begin{tabular}{lccc}
\hline & $\begin{array}{c}\text { Women with } \\
\text { GDM } \\
\mathbf{n}=\mathbf{2 5 1}(\%)\end{array}$ & $\begin{array}{c}\text { Comparison } \\
\text { group } \\
\mathbf{n}=\mathbf{5 9 7}(\%)\end{array}$ & p-value \\
\hline Women & $68(27.1 \%)$ & $83(13.9 \%)$ & $<0.001$ \\
$\begin{array}{l}\text { Induction of labour } \\
\text { Mode of delivery }\end{array}$ & $198(78.9 \%)$ & $508(85.1 \%)$ & \\
Vaginal delivery & $53(21.1 \%)$ & $89(14.9 \%)$ & 0.027 \\
Caesarean section & & & \\
Newborn & 1 & 11 & \\
Serious perinatal & & & \\
complication & $0(0.0 \%)$ & $0(0.0 \%)$ & - \\
Death & $0(0.0 \%)$ & $3(0.5 \%)$ & 0.56 \\
Shoulder dystocia & $1(0.4 \%)$ & $8(1.3 \%)$ & 0.22 \\
Bone fracture & $0(0.0 \%)$ & $0(0.0 \%)$ & - \\
Nerve palsy & $4(1.6 \%)$ & $4(0.7 \%)$ & 0.20 \\
Respiratory care & $0(0.0 \%)$ & $0(0.0 \%)$ & - \\
Blood change & $31(12.4 \%)$ & $56(9.4 \%)$ & 0.19 \\
Phototherapy & $5(2.0 \%)$ & $1(0.2 \%)$ & 0.010 \\
Resuscitation & $25(10.0 \%)$ & $50(8.4 \%)$ & 0.46 \\
Antibiotic treatment & & & \\
\hline
\end{tabular}

antenatal clinic during their pregnancy [28]. The recommended number of visits to antenatal care providers for multiparous women is $10-14$ [28]. However, GDM is associated with increased outpatient costs due to visits

Table 5 Summary of allocation of mean costs to the patient and municipality among women with and without a GDM diagnosis and their newborn

\begin{tabular}{|c|c|c|c|}
\hline & $\begin{array}{c}\text { Women with } \\
\text { GDM } \\
n=251\end{array}$ & $\begin{array}{c}\text { Comparison } \\
\text { group } \\
n=597\end{array}$ & $p$-value \\
\hline & $€$ & $€$ & \\
\hline \multicolumn{4}{|l|}{ Women } \\
\hline Outpatient costs* & 1,726 & 1,342 & $\begin{array}{l}p< \\
0.001\end{array}$ \\
\hline Inpatient costst & 491 & 341 & $\begin{array}{l}p< \\
0.001\end{array}$ \\
\hline Delivery costs $\neq$ & 2,249 & 2,149 & $\begin{array}{c}p= \\
0.054\end{array}$ \\
\hline Other costs§ & 50 & 25 & \\
\hline \multicolumn{4}{|l|}{ Newborn } \\
\hline $\begin{array}{l}\text { Neonatal intensive care unit } \\
\text { costs } \neq\end{array}$ & 1,916 & 1,286 & $\begin{array}{l}p< \\
0.001\end{array}$ \\
\hline Total costs & 6,432 & 5,143 & $\begin{array}{l}p< \\
0.001\end{array}$ \\
\hline
\end{tabular}

*Sum of costs associated to visits to primary and secondary care.

†Sum of costs associated to inpatient days before and after delivery.

¥Sum of cost to the patient and the municipality.

$\S$ Cost of oral glucose tolerance test $(25 €)+$ medication. to secondary care, which was almost three times higher than the cost of a visit to a public health nurse or a doctor working in primary health care.

According to earlier studies being overweight, especially as a GDM risk factor, imposes a considerable and increasing burden on health services [11,12]. According to data from the Medical Birth Register for $2006(\mathrm{~N}=59,053), 34.2 \%$ of the women had at least one GDM risk factor and, of these, $20.4 \%$ had a confirmed GDM diagnosis [10]. According to our earlier study [10], the mean costs of primary health care visits, including the costs of OGTTs, were $40.5 \%$ higher among women with at least one GDM risk factor and a GDM diagnosis than among women without any risk factors or a GDM diagnosis. Even being moderately overweight before pregnancy correlated with higher hospitalisation costs [11]. In addition, total outpatient and inpatient costs were three times higher among the severely prepregnancy obese $\left(\mathrm{BMI}>35 \mathrm{~kg} / \mathrm{m}^{2}\right)$ than among women of normal weight (BMI $<25 \mathrm{~kg} / \mathrm{m}^{2}$ ) [11].

All participants in our study had a risk of GDM, which may increase pre-and postnatal health care costs. We have previously reported that the costs of visits to antenatal health care to see a doctor or a public health nurse did not differ according to the woman's confirmed GDM status [10]. However, there were statistically significant differences between the numbers of visits and the costs of the group with neither GDM risk factors nor a GDM diagnosis and the group with at least one GDM risk factor and a confirmed GDM diagnosis [10].

This study had a number of limitations. For example, there was a risk of confounding which may reduce internal validity. However conditions such as elevated blood pressure were evenly distributed among groups which appears to offset this limitation. Another weakness was that the cost evaluation of inpatient days was based on inpatient days on wards related to pregnancy and gestational diabetes care. The use of ICD-10 diagnosis codes as inclusion criteria would have been more reliable for quantifying relevant inpatient days. On the other hand, GDM may increase the number of inpatient days for various reasons, which was a reason for the use of our current inclusion criteria. In addition, the study may underestimate the inpatient and outpatient days occurring after delivery, because readmissions were not taken into consideration. The costs were taken into account until the last day the mother or baby spent in hospital directly after birth, which was a precise cutpoint for cost evaluation.

Another potential limitation concerned unit costs, which were those of the Tampere University Hospital [24] and average national unit costs [23]. Health care costs were based on secondary care unit costs of one 
hospital district [24], which has to be taken into consideration when interpreting the study findings. However, the use of Tampere University Hospital unit costs provided an opportunity to evaluate secondary care costs in detail as the data available on national average health care costs did not include detailed delivery costs or costs of surgery based on ICD-10 diagnosis codes. The unit costs of the Tampere University Hospital [24] were similar to average national costs, partly because the Tampere University Hospital is a part of the Pirkanmaa Hospital District, which is the second biggest hospital district in Finland. Our study included only health care costs associated with GDM, but omitted economic costs such as the cost of productivity loss, which is a further limitation. Thus the total health care costs of gestational diabetes mellitus among high-risk women may have been underestimated. Since the data was based on a randomised intervention, the possibility that the intervention had an effect on GDM incidence cannot be denied. However, there were no differences between the trial groups in GDM incidence [21] and thus the intervention probably did not have an effect on the total cost of GDM.

\section{Conclusion}

The study findings emphasize the potential importance of prevention programmes in saving money and improving the health of mothers and newborn babies. In further studies, it would be useful to evaluate the costeffectiveness of health promotion programmes among GDM patients.

\section{Competing interests}

The authors have no competing interests.

\author{
Authors' contributions \\ PK wrote the manuscript and researched the data, JR performed the \\ statistical analysis. RL and PR reviewed and edited the manuscript and \\ contributed to the discussion. All authors have approved the final form of \\ the manuscript.
}

\section{Acknowledgements}

The article was funded by the Juho Vainio Foundation, the Yrjö Jahnsson Foundation, medical research funding from Tampere University Hospital (competitive research funding from the Pirkanmaa Hospital District), the Academy of Finland, and the Ministry of Education and the Ministry of Social Affairs and Health.

\author{
Author details \\ ${ }^{1}$ UKK Institute for Health Promotion Research, Kaupinpuistonkatu 1, FI-33501, \\ Tampere, Finland. ${ }^{2}$ School of Health Sciences, University of Tampere, \\ Tampere, Finland. \\ Received: 16 December 2011 Accepted: 26 June 2012 \\ Published: 24 July 2012 \\ References \\ 1. American Diabetes Association: Gestational diabetes mellitus. Diabetes \\ Care 2004, 27(Suppl 1):S88-90.
}

2. Kieffer EC, Sinco B, Kim C: Health behaviors among women of reproductive age with and without a history of gestational diabetes mellitus. Diabetes Care 2006, 8:1788-1793.

3. Chu SY, Callaghan WM, Kim SY, Schmid CH, Lau J, England LJ, Dietz PM: Maternal obesity and risk of gestational diabetes mellitus. Diabetes Care 2007, 8:2070-2076.

4. Teh WT, Teede HJ, Paul E, Harrison CL, Wallace EM, Allan C: Risk factors for gestational diabetes mellitus: implications for the application of screening guidelines. Aust N Z J Obstet Gynaecol 2011, 1:26-30. doi:10.1111/j.1479-828X.2011.01292.x.

5. Bener A, Saleh NM, Al-Hamaq A: Prevalence of gestational diabetes and associated maternal and neonatal complications in a fast-developing community: global comparisons. Int J Womens Health 2011, 3:367-73.

6. Lamberg S, Raitanen J, Rissanen P, Luoto R: Prevalence and regional differences of gestational diabetes mellitus and oral glucose tolerance tests in Finland. Eur J Public Health 2012, 2:278-280.

7. Ferrara A: Increasing prevalence of gestational diabetes mellitus: a public health perspective. Diabetes Care 2007, 30(Suppl. 2):S141-146.

8. Chen Y, Quick WW, Yang W, Zhang Y, Baldwin A, Moran J, Moore V, Sahai N, Dall TM: Cost of gestational diabetes mellitus in the United States in 2007. Popul Health Manag 2009, 12:165-174.

9. Wier LM, Witt E, Burgess J, Elixhauser A: Hospitalizations related to diabetes in pregnancy, 2008: statistical brief \#102. In: Healthcare Cost and Utilization Project (HCUP).HCUP Statistical Briefs. Rockville (MD). Agency for Health Care Policy and Research (US) 2006, http://www.ncbi.nlm. nih.gov/books/NBK52649/.

10. Kolu P, Raitanen J, Luoto R: Cost of gestational diabetes-related antenatal visits in health care based on the Finnish Medical Birth Register. Prim Care Diabetes 2011, 5:139-141.

11. Galtier-Dereure F, Montpeyroux F, Boulot P, Bringer J, Jaffiol C: Weight excess before pregnancy: complications and cost. Int J Obes Relat Metab Disord 1995, 19:443-448.

12. Galtier-Dereure F, Boegner C, Bringer J: Obesity and pregnancy: complications and cost. Am J Clin Nutr 2000, 71(Suppl 5):1242S-1248S.

13. Casey BM, Lucas MJ, Mcintire DD, Leveno KJ: Pregnancy outcomes in women with gestational diabetes compared with the general obstetric population. Obstet Gynecol 1997, 90:869-873.

14. Schneider S, Hoeft B, Freerksen N, Fischer B, Roehrig S, Yamamoto S, Maul $\mathrm{H}$ : Neonatal complications and risk factors among women with gestational diabetes mellitus. Acta Obstet Gynecol Scand 2010, 16. 10.1111/j.1600-0412.2010.01040.x.

15. Ben-Haroush A, Yogev $Y$, Hod M: Epidemiology of gestational diabetes mellitus and its association with Type 2 diabetes. Diabet Med 2004, 21:103-113.

16. Gregory KD, Kjos SL, Peters RK: Cost of non-insulin-dependent diabetes in women with a history of gestational diabetes: implications for prevention. Obstet Gynecol 1993, 81:782-786.

17. Davenport MH, Campbell MK, Mottola MF: Increased incidence of glucose disorders during pregnancy is not explained by pre-pregnancy obesity in London, Canada. BMC Pregnancy Childbirth 2010, 10:85.

18. Meltzer SJ, Snyder J, Penrod JR, Nudi M, Morin L: Gestational diabetes mellitus screening and diagnosis: a prospective randomised controlled trial comparing costs of one-step and two-step methods. BJOG 2010, 117:407-415.

19. Nicholson WK, Fleisher LA, Fox HE, Powe NR: Screening for gestational diabetes mellitus: a decision and cost-effectiveness analysis of four screening strategies. Diabetes Care 2005, 28:1482-1484.

20. Kim C, Herman WH, Vijan S: Efficacy and cost of postpartum screening strategies for diabetes among women with histories of gestational diabetes mellitus. Diabetes Care 2007, 30:1102-1106.

21. Luoto R, Kinnunen TI, Aittasalo A, Kolu P, Raitanen J, Ojala K, Mansikkamäki K, Lamberg S, Vasankari T, Komulainen T, Tulokas S: Primary prevention of gestational diabetes mellitus and large-for-gestational-age newborns by lifestyle counseling -a cluster-randomized controlled trial. PLoS Medicine 2011, 8:e1001036.

22. Luoto RM, Kinnunen TIM, Aittasalo Ojala K, Mansikkamäki K, Toropainen E, Kolu P, Vasankari T: Prevention of gestational diabetes: design of a cluster-randomized controlled trial and one-year follow-up. BMC Pregnancy Childbirth 2010, 10:39.

23. Hujanen T, Kapiainen S, Tuominen U, Pekurinen M: Terveydenhuollon yksikkökustannukset Suomessa vuonna 2006 Health care unit costs in 
Finland 2006 (in Finnish). In National Research and Development Centre for Welfare and Health. Edited by. Helsinki: The National Institute for Health and Welfare; 2008.

24. Pirkanmaa Hospital District: Products and prices. Tampere: Pirkanmaa Hospital District; 2009.

25. The Finnish Current Care Guidelines for GDM; 2008. http:/www.kaypahoito.fi/.

26. Souza JP, Gülmezoglu A, Lumbiganon P, Laopaiboon M, Carroli G, Fawole B, Ruyan P: WHO global survey on maternal and perinatal health research group caesarean section without medical indications is associated with an increased risk of adverse short-term maternal outcomes: the 2004-2008 WHO global survey on maternal and perinatal health. BMC Med 2010, 8:71.

27. The National Institute for Health and Welfare: Finnish Medical Birth Registry: The National Institute for Health and Welfare; 2004

28. Viisainen $\mathrm{K}$ : Screening and collaboration in prenatal care. In Edited by Viisainen K. Gummerus, Helsinki: Stakes oppaita 34 (in Finnish); 1999.

doi:10.1186/1471-2393-12-71

Cite this article as: Kolu et al:: Health care costs associated with gestational diabetes mellitus among high-risk

women - results from a randomised trial. BMC Pregnancy and Childbirth $201212: 71$

\section{Submit your next manuscript to BioMed Central and take full advantage of:}

- Convenient online submission

- Thorough peer review

- No space constraints or color figure charges

- Immediate publication on acceptance

- Inclusion in PubMed, CAS, Scopus and Google Scholar

- Research which is freely available for redistribution 